\title{
Article \\ Hyaluronic Acid-Coated MTX-PEI Nanoparticles for Targeted Rheumatoid Arthritis Therapy
}

\author{
Shenghui Zhong ${ }^{1,2}$, Peng Liu ${ }^{1}$, Jinsong Ding ${ }^{1, *}$ and Wenhu Zhou ${ }^{1, *}$ \\ 1 Xiangya School of Pharmaceutical Sciences, Central South University, Changsha 410013, Hunan, China; \\ zhongsh1988@126.com (S.Z.); liupengpharmacy@163.com (P.L.) \\ 2 School of Medicine, Yichun University, Yichun 336000, Jiangxi, China \\ * Correspondence: dingjs0221@163.com (J.D.); zhouwenhuyaoji@163.com (W.Z.)
}

check for updates

Citation: Zhong, S.; Liu, P.; Ding, J.; Zhou, W. Hyaluronic Acid-Coated MTX-PEI Nanoparticles for Targeted Rheumatoid Arthritis Therapy. Crystals 2021, 11, 321. https:// doi.org/10.3390/cryst11040321

Academic Editor: Duane Choquesillo-Lazarte

Received: 26 February 2021

Accepted: 22 March 2021

Published: 24 March 2021

Publisher's Note: MDPI stays neutral with regard to jurisdictional claims in published maps and institutional affiliations.

Copyright: (c) 2021 by the authors. Licensee MDPI, Basel, Switzerland. This article is an open access article distributed under the terms and conditions of the Creative Commons Attribution (CC BY) license (https:/ / creativecommons.org/licenses/by/ $4.0 /)$.

\begin{abstract}
Methotrexate (MTX) is an anchor drug for the treatment of rheumatoid arthritis (RA); however, long-term and high-dose usage of MTX for patients can cause many side effects and toxic reactions. To address these difficulties, selectively delivering MTX to the inflammatory site of a joint is promising in the treatment of RA. In this study, we prepared MTX-PEI@HA nanoparticles (NPs), composed of hyaluronic acid (HA) as the hydrophilic negative electrical shell, and MTX-linked branched polyethyleneimine (MTX-PEI) NPs as the core. MTX-PEI@HA NPs were prepared in the water phase by a one-pot method. The polymeric NPs were selectively internalized via CD44 receptormediated endocytosis in the activated macrophages. In the in vivo mice mode study, treatment with MTX-PEI@HA NPs mitigated inflammatory arthritis with notable safety at a high dose of MTX. We highlight the distinct advantages of aqueous-synthesized NPs coated with HA for arthritis-selective targeted delivery, thus verifying MTX-PEI@HA NPs as a promising MTX-based nanoplatform for treatment of RA.
\end{abstract}

Keywords: methotrexate; polyethyleneimine; rheumatoid arthritis; nanoparticles; target therapy

\section{Introduction}

Rheumatoid arthritis (RA) is a systemic autoimmune disease characterized by chronic synovial joint inflammation, which can cause disability and poor quality of life [1,2]. Although the pathogenesis of RA remains uncertain, activated macrophages have been found to be the most prominent cells in the arthritis tissue of patients with RA and are considered as the main cause of articular inflammation and joint damage pathogenesis [3,4]. Therefore, the targeting of activated macrophages and inflammatory cytokines such as tumor necrosis factor- $\alpha$ has been regarded as an effective form of RA therapy [5,6]. Disease modifying anti-rheumatic drugs (DMARDs) are the main method for the symptom relief and radiographic progression control in RA [5,7,8]. There are several DMARDs available for RA therapy. Since the re-introduction of methotrexate (MTX) in the early $1980 \mathrm{~s}$, MTX has become the most highly effective, fast-acting, disease modifying anti-rheumatic drug and is one of the most widely used and the first-line DMARD for the treatment of RA [9-11]. However, long-term treatment with MTX is routinely associated with a gradual decrease in drug efficiency which could point to the onset of drug resistance. Increasing dosage and administration frequency could regain therapeutic efficacy, but this approach is hindered by the significantly increased adverse effects, such as myelosuppression, dysfunction of the liver, rash and so forth [12-14]. In fact, clinical studies have demonstrated that maintaining low plasma concentration of MTX is beneficial to controlling RA inflammation and improving bioavailability. It has inspired us to develop the sustained-release preparation of MTX, which may have advantages over increasing dosage and administration frequency in the treatment of RA $[15,16]$. One strategy for achieving the goal is to design a nanoplatform delivering MTX, which targets the drug to activated macrophages in the inflamed joints of RA and releases MTX in a slow profile. 
Nowadays, nanotechnology is developing rapidly and its application in biomedical field is growing fast [17]. In recent years, nanomedicine has shown their inherent superiority in diagnosis and treatment in RA with the merit of stable drug encapsulation, controllable drug release behavior, prolonged drug retention time and lower toxicity [18-20]. Present studies show that the vascular permeability is dramatically improved in the RA site because of the abnormal vessels and inflammatory cell infiltration. This allows for the passive accumulation of nanoparticles (NPs) in inflammatory joint tissue through what we called the "ELVIS" effect (extravasation through leaky vasculature and subsequent inflammatory cell-mediated sequestration), similar to the EPR (enhanced permeability and retention) effect observed in solid tumors [21,22]. Moreover, NPs can also actively target arthritis joints via surface modifications of specific recognition ligands (hyaluronic acid, folic acid) due to inflammation-associated macrophages (a key cellular target for RA treatment) pathologically overexpressing certain receptors (CD44, folic acid receptor) on the cell membrane $[16,23]$. However, the preparation process of nanomedicine delivery systems is usually complex currently, and organic solvents are commonly needed, which leads to residual organic solvents inevitably and may cause serious toxic effects in vivo [17,24,25]. Studies have shown that MTX could be loaded via different nanoplatform construction strategies, such as direct physical encapsulation, coordination and covalent conjugation. While physical and coordination encapsulation of MTX are simpler than covalent conjugation in preparation, it is common for drug leakage to occur during in vivo circulation before NPs reaching the target tissue and cells $[18,19]$. These challenges hinder the application of MTX NPs in the treatment of RA $[17,26]$. Therefore, it is worth trying to design an active targeting MTX delivery system which is easy to prepare and avoid drug leakage.

Hyaluronic acid (HA), which possesses diverse desirable physicochemical and biological properties, has been widely applied for drug delivery [27,28]. Extensive researches have shown that HA-coated NPs can target the RA inflammatory site effectively due to the interaction between HA and CD44 receptors, which is highly expressed in RA joint tissue [29-31]. To effectively deliver MTX to the inflamed joints in RA, here MTX-PEI NPs were fabricated in the water phase using a facile one-pot method without organic solvent, then coated by HA via electrostatic interactions. We hypothesized that HA surface of the nanoparticle allows for specific binding to HA-related receptors (CD44) on activated macrophages, followed by receptor-mediated endocytosis and intracellular release of MTX (Scheme 1).

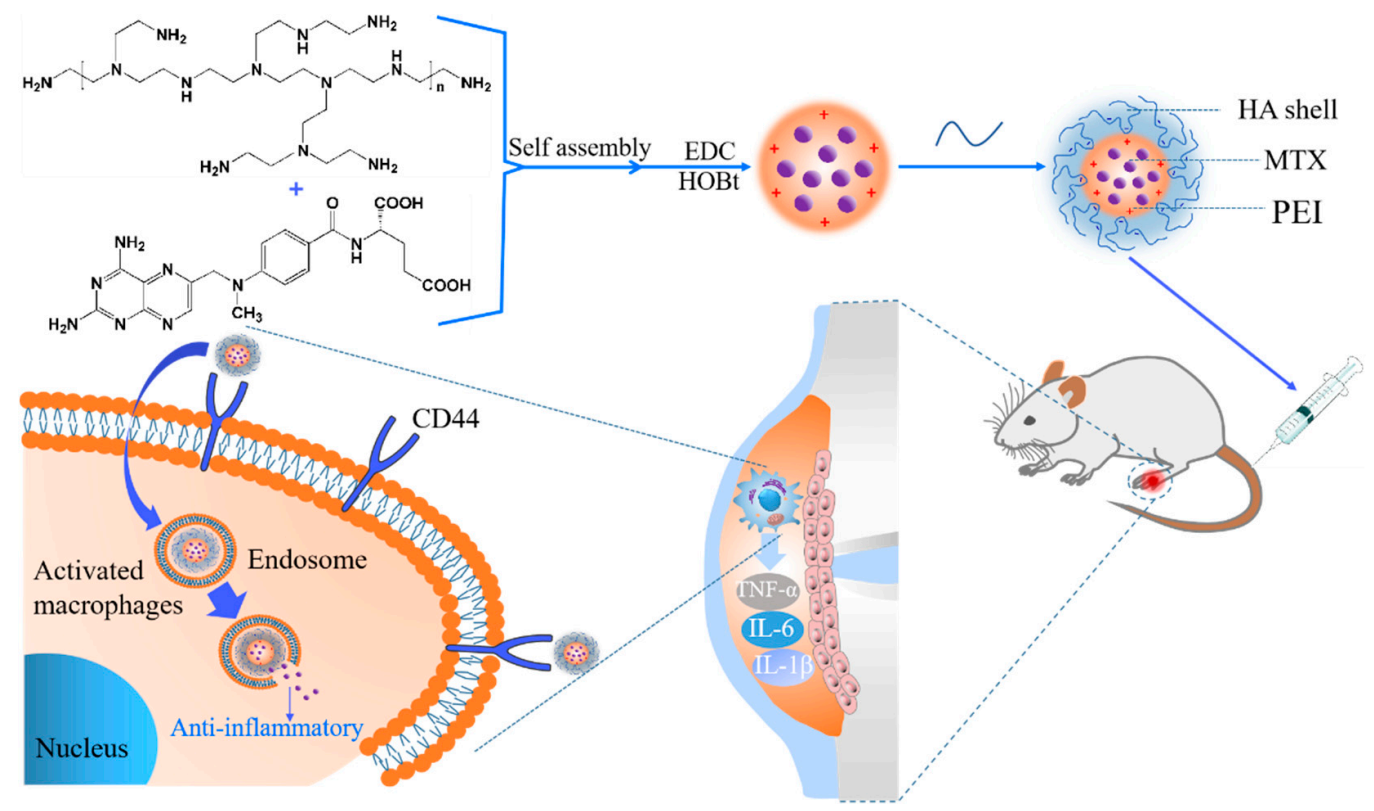

Scheme 1. Schematic illustration of the whole experimental process, including preparation, intravenous injection and intracellular fate of polymeric hyaluronic acid methotrexate-linked branched polyethyleneimine (MTX-PEI@HA) nanoparticles (NPs). 


\section{Materials and Methods}

\subsection{Materials, Cells and Animals}

\subsubsection{Materials}

Methanol (high-performance liquid chromatography (HPLC) grade) was obtained from Tedia Co., Ltd (Fairfield, OH, USA). PVP K30 (44-54 kDa) Methotrexate (MTX), Hyaluronic acid (HA, MW = 12-25 kDa), 5-carboxyfluorescein (5-FAM) were obtained from Shanghai Yuanye Biotechnology Co., Ltd (Shanghai, China). Lipopolysaccharide (LPS) was purchased from Biosharp Co., Ltd (Beijing, China). Bovine type II collagen was purchased from Chondrex (Washington, DC, USA). Polyethyleneimine (PEI, MW $=25 \mathrm{kDa}$ ), 1-hydroxybenzotriazole (HOBt), 1-ethyl-3/3-dimethyl aminopropyl carbodiimide (EDC), 3-(4,5-dimethylthiazol-2-yl)-2,5-diphenyl tetrazolium bromide (MTT), complete Freund's adjuvant and incomplete Freund's adjuvant were obtained from Sigma-Aldrich Co., Ltd (St. Louis, MO, USA). Phosphate buffered saline (PBS), Dulbecco's modified Eagle's medium (DMEM), penicillin-streptomycin solution, and fetal bovine serum (FBS) were obtained from Gibco Life Technologies, Inc. (Grand Island, NY, USA).

\subsubsection{Cells}

The murine macrophage cell line (RAW264.7) was purchased from Xiangya cell center (Changsha, China). The cells were cultivated in DMEM medium supplemented with $1 \%$ penicillin $(50 \mathrm{U} / \mathrm{mL}), 10 \% \mathrm{FBS}$ and streptomycin $(50 \mathrm{U} / \mathrm{mL})$ in a $5 \% \mathrm{CO}_{2}$ atmosphere at $37^{\circ} \mathrm{C}$.

\subsubsection{Animals}

DBA/1J male mice ( $20 \pm 2 \mathrm{~g})$ aged 7-8 weeks old were obtained from Cavens animal Co., Ltd. (Changzhou, China), and kept in a pathogen-free environment and provided with sufficient food and water. All animal experiments were performed following the requirements the National Act on the Use of Experimental Animals (People's Republic of China) and were permitted by the Experimental Animal Ethics Committee of Central South University.

\subsection{Methods}

2.2.1. Preparation of Hyaluronic Acid Methotrexate-Linked Branched Polyethyleneimine (MTX-PEI@HA) Nanoparticles (NPs)

We added $5 \mathrm{~mL}$ of $0.5 \%$ PEI aqueous solution quickly to $5 \mathrm{~mL}$ of $2 \mathrm{mM}$ MTX HEPEs buffers (Ph = 7.4), and then stirred it quickly. Then, $100 \mathrm{mg}$ PVP K30, $3.83 \mathrm{mg}$ EDC, $1.35 \mathrm{mg}$ HOBt were added rapidly and stirred for $12 \mathrm{~h}$. The reaction solution was processed by a $15 \mathrm{~min}, 20,000 \mathrm{rpm}$ centrifugation in a centrifuge and the precipitated was washed by ultrapure water three times. The MTX-PEI NPs obtained were quickly dispersed in $1 \mathrm{mg} / \mathrm{mL}$ HA solution and stirred for $4 \mathrm{~h}$, then centrifuged to obtain MTX-PEI@HA NPs and washed away the residual HA with ultrapure water at last.

\subsubsection{Characterization of MTX-PEI@HA}

Particle size and zeta potential of MTX-PEI and MTX-PEI@HA were determined by dynamic light scattering (DLS) analysis using Malvern Zeta Sizer Nano series (Nano ZS, Malvern instruments, Malvern, UK). The morphologies were observed by using transmission electron microscopy (TEM) (Titan G2-F20, FEI, Hillsboro, OR, USA). HPLC was performed to determine the amount of MTX loaded within the NPs. Loading efficiency of MTX/PEI and MTX-PEI were determined using the equation: loading efficiency $(\%)=($ the amount of drug loaded)/(amount of drug before loading) $\times 100 \%$.

\subsubsection{In Vitro Drug Release Profile}

The in vitro release behavior of MTX from MTX-PEI was studied by the centrifugation method. Briefly, MTX-PEI was mixed with PBS (pH 7.4, $10 \mathrm{mM})$ placed in a thermostatic shaker $\left(100 \mathrm{rpm}, 37^{\circ} \mathrm{C}\right)$. At pre-designated time intervals $(0.5,1,2,4,8,12,24,48 \mathrm{~h})$, 
$0.5 \mathrm{~mL}$ of dissolution medium was taken out and centrifuged at $20,000 \times g$ for $15 \mathrm{~min}$. The supernatant was analyzed by the HPLC. The chromatographic conditions were as follows: Diamonsil C18 column $(250 \mathrm{~mm} \times 4.6 \mathrm{~mm}, 5 \mu \mathrm{m})$ with the temperature of $35^{\circ} \mathrm{C}$, methanolPBS $(0.02 \mathrm{M}, \mathrm{pH} 6.5)=20: 80(v / v)$ as mobile phase with the flow rate of $1 \mathrm{~mL} / \mathrm{min}$. The ultraviolet (UV) detection was performed at $302 \mathrm{~nm}$.

\subsubsection{Real-Time Polymerase Chain Reaction (RT-PCR) Detection}

The RAW264.7 cells were seeded onto 6-well plates at density of $2 \times 10^{5}$ cells per well and cultured for $48 \mathrm{~h}$ in the absence or presence of lipopolysaccharide (LPS, $10 \mu \mathrm{g} / \mathrm{mL}$ ). After $48 \mathrm{~h}$, the cells were collected and total RNA was extracted by using TRIzol reagent. The levels of mRNAs (including iNOS, TNF- $\alpha$, IL-1 $\beta$ and IL-6) were detected by real-time polymerase chain reaction (RT-PCR, CFX-Connect, BIO-RAD, Hercules, CA, USA). Primer sequences were designed by soft of primer 5.0 (Table 1 ).

Table 1. Primer sequences used for real-time polymerase chain reaction (PCR).

\begin{tabular}{ccc}
\hline Gene & Forward Primer $\left(\mathbf{5}^{\prime}\right.$ to $\left.\mathbf{3}^{\prime}\right)$ & Reverse Primer $\left(\mathbf{5}^{\prime}\right.$ to $\mathbf{3}^{\prime} \mathbf{)}$ \\
\hline IL-1 $\beta$ & ATGAAGGGCTGCTTCCAAAC & TCTCCACAGCCACAATGAGT \\
IL-6 & GGAGCCCACCAAGAACGATA & ACCAGCATCAGTCCCAAGAA \\
TNF- $\alpha$ & CTCATGCACCACCATCAAGG & ACCTGACCACTCTCCCTTTG \\
iNOS & CAGCTGGGCTGTACAAACCTT & CATTGGAAGTGAAGCGTTTCG \\
\hline
\end{tabular}

\subsubsection{Cellular Uptake Study}

The RAW264.7 cells were seeded onto 24-well plates at density of $4 \times 104$ cells per well, and incubated with or without LPS $(10 \mu \mathrm{g} / \mathrm{mL})$ for $48 \mathrm{~h}$. Next, the cells were incubated with 5-FAM-labelled NPs for $4 \mathrm{~h}$. Then, residual nanoparticles in the culture medium were removed via washing three times with PBS ( $\mathrm{pH} 7.4$ ). The cells were fixed with $4 \%$ paraformaldehyde for $20 \mathrm{~min}$ and incubated with DAPI (4',6-diamidino-2-phenylindole) solution $(10 \mu \mathrm{g} / \mathrm{mL})$ for $10 \mathrm{~min}$ to stain nucleus. NPs internalization was evaluated via using fluorescent microscopy. The cells were seeded onto 6-well plates at density of $2 \times 105$ cells per well, and the same treatments were carried out as described above to quantify the internalization. The cells were collected and the fluorescence intensity was evaluated via using flow cytometry (FACSVerse, BD, Lake Franklin, NJ, USA) after washing in triplet with PBS (pH 7.4). To further study the uptake mechanism, the cells were pretreated with $5 \mathrm{mg} / \mathrm{mL}$ HA for $1 \mathrm{~h}$ before incubating with 5-FAM-labelled NPs.

\subsubsection{In Vitro Cytotoxicity Study}

RAW264.7 cells were seeded onto 96-well plates at density of $2 \times 10^{3}$ per well and incubated with LPS $(10 \mu \mathrm{g} / \mathrm{mL})$ to activate the cells for $48 \mathrm{~h}$. The cells were treated with different formulations (diluted by cell culture medium) for $72 \mathrm{~h}$ after removing the medium and washing twice with PBS. Then, $20 \mu \mathrm{L}$ of MTT solution $(5 \mathrm{mg} / \mathrm{mL})$ was added. $100 \mu \mathrm{L}$ of DMSO was added after $4 \mathrm{~h}$ incubation, and microplate reader (Infinite M200 PRO, TECAN, Graz, Austria) was used to detect the absorbance at $490 \mathrm{~nm}$.

\subsubsection{Mice Model of Collagen-Induced Arthritis}

We established the collagen-induced arthritis (CIA) mice model according to a previous report [32] First, to prepare two emulsions, incomplete Freund's Adjuvant (for B emulsion) or Complete Freund's Adjuvant (for A emulsion) was mixed with an equal volume of $2 \mathrm{mg} / \mathrm{mL}$ bovine type II collagen for overnight stirring in an ice bath. The mice were injected subcutaneously at a distance from the base of the tail by using $0.1 \mathrm{~mL} \mathrm{~A}$ emulsion on day 0 . B emulsion was used for a booster injection on day 21 . To observe the arthritis progression, mice were monitored daily. 


\subsubsection{Therapeutic Efficacy In Vivo}

The CIA mice were divided into 4 groups $(n=5)$ for tail intravenous injection of saline, MTX, MTX-PEI or MTX-PEI@HA NPs (5 mg/ kg, MTX/body weight). The injection was started at days 42 after the first immunization, and the mice were treated with different formulations every two days for 5 times intravenous injection in total. The body weight and hind paw thickness were measured and recorded every other day. The arthritis scores of each paw was assessed from 0 to 4 according to the following scale: $0=$ no evidence of erythema or swelling, $1=$ erythema and mild swelling, 2 = erythema and mild swelling extending from the ankle to the tarsals, 3 = erythema and moderate swelling extending from the ankle to metatarsal joints, and $4=$ erythema and severe swelling encompassing the ankle, foot, and digits or ankylosis of the limb [33]. The maximum total arthritis score of each mouse was 16 . Joint tissues were collected on day 50 after the first immunization.

\subsubsection{Histological Analysis}

The mice were sacrificed, and spleen, kidney, liver and ankle joints were harvested and fixed in $4 \%$ paraformaldehyde overnight after treatments. We used 10\% EDTA solution to decalcify ankle joints for 40 days. Then, the decalcified joints were embedded in paraffin and sliced into $4 \mu \mathrm{m}$-thick sections. The joints sections were stained with hematoxylin-eosin (H\&E). A light microscope (Model IX71 Olympus, Tokyo, Japan) was used to obtain the images of sections. The cartilage erosion of ankle joints and histological changes with synovial inflammation were assessed by HSS (histopathological scores of synovium) [34,35].

\subsubsection{Safety Evaluation In Vivo}

To evaluate the safety of each formulation, the serum of mice was collected after treatment, and the levels of aspartate aminotransferase (AST), alanine aminotransferase (ALT), blood urea nitrogen (BUN) and creatinine (Cre) were measured by using the standard kits according to the manufacturer's instructions.

\subsubsection{Statistical Analysis}

All experimental data were expressed as mean \pm standard deviation (SD), from at least triplicate measurements. The statistical significance between two comparative groups were analyzed by the Student's t-test, and the differences among multiple groups was tested by one-way analysis of variance (ANOVA). Significance was assessed by the two-tailed unpaired Student's $t$-test with a value of ${ }^{*} p<0.05,{ }^{* *} p<0.01,{ }^{* * *} p<0.001$.

\section{Results and Discussion}

3.1. Formation of MTX/PEI NPs and Mechanism Understanding of the Interaction between MTX and PEI

Drug loading via electrostatic interaction is a straightforward method in nanoplatform. The realization of drug loading via electrostatic force requires adequate electrostatic interaction between the carrier and drug molecules with opposite charge properties. Cationic polymer has been widely studied and used in the field of gene delivery [36]. One of the most successful and widely studied gene-delivery polymers reported to date is PEI because of its high density of cations [37]. When MTX is in neutral condition, drug molecules are negative. Therefore, here, we tried to use cationic polymer PEI as MTX carrier to achieve high loading and efficient delivery of MTX. In order to explore its possibility, we first studied the interaction between methotrexate and PEI.

We mixed PEI of different concentration with MTX of $2 \mathrm{mM}$ in equal volume and found that the mixed solution showed opalescence with the increase of PEI mass concentration. The mixed solution became clear again with the increase of PEI concentration further (Figure 1a). DLS size was found to decrease with the concentration of PEI (Figure 1a). The amount of MTX wrapped by PEI in different concentrations was calculated by determination of free MTX in supernatant via HPLC. The entrapment efficiency of MTX increased with the rise of PEI concentration and reached the maximum mean value of $86.3 \%$ when 
final PEI concentration was $0.015 \%$ (Figure $1 \mathrm{~b}$ ). Furthermore, the particle size was also suitable under the condition. The encapsulation efficiency of MTX decreased with the further increase of PEI concentration. Therefore, we choose $0.015 \%$ PEI (final concentration) and $1 \mathrm{mM}$ MTX (final concentration) for further study.

We further explored the interaction mechanism between MTX and PEI. The precipitation of MTX/PEI was dispersed in urea solution and $\mathrm{NaCl}$ solution of different concentration respectively and incubated for $30 \mathrm{~min}$. Urea is considered to be a good chemical substance for shielding hydrogen bonding [38]. On the other hand, $\mathrm{NaCl}$ solution can compromise electrostatic interaction effectively [39]. Similarly, the amount of MTX dissociation from PEI was further calculated by determining the supernatant after centrifugation. We found that the dissociation rate of MTX increased with the rise of urea concentration (Figure 1c). The dissociation rate of MTX also increased with the rise of $\mathrm{NaCl}$ concentration and reached the maximum mean value of $56.2 \%$ at the concentration of $200 \mathrm{mmol}$ (Figure 1d). These results indicated that hydrogen bond and electrostatic interaction were the driving forces for MTX/PEI NPs formation, in which electrostatic force played the key role. Considering that the NPs obtained by electrostatic interaction are easy to disintegrate under physiological conditions and lead to drug leakage, the chemical bonding method was used to optimize the preparation based on MTX/PEI NPs.
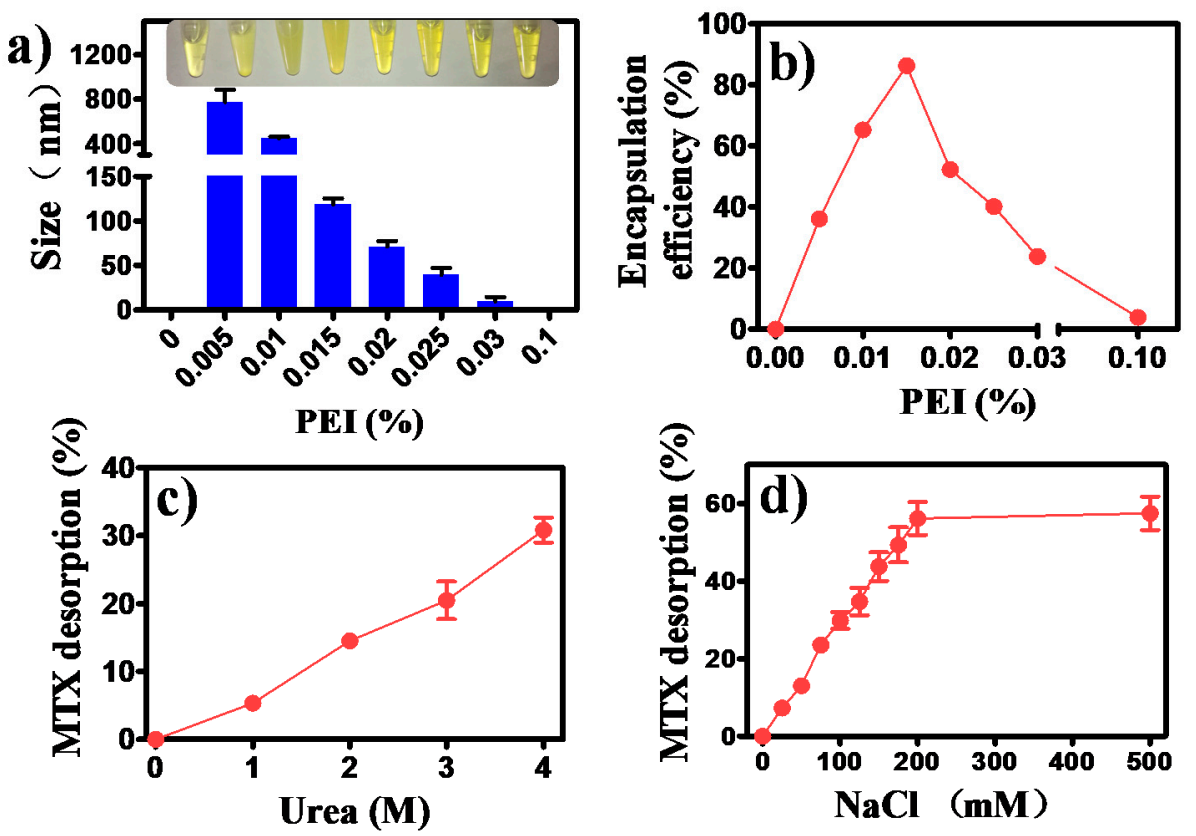

Figure 1. The formation of MTX/PEI NPs and mechanism understanding of the interaction between MTX and PEI. (a) Appearance and dynamic light scattering (DLS) size of MTX/PEI mixture changed with PEI concentration. (b) MTX encapsulation efficiency changed with the increasing concentration of PEI. (c,d) MTX desorption rate increased with urea concentration and $\mathrm{NaCl}$ concentration.

\subsection{Systematical Characterization of MTX-PEI@HA NPS}

The high desorption rate of MTX in $\mathrm{NaCl}$ solution indicated that MTX/PEI nanocomposites are easy to dissociate under physiological conditions. Therefore, we added EDC and HOBt to MTX/PEI NPs solution for conjugating the primary amine group of PEI and carboxyl group of MTX. 1\% PVP K30 was added to prevent MTX/PEI nanocomposites from aggregation immediately. After stirring for $12 \mathrm{~h}$ at room temperature, MTX-PEI NPs were obtained by centrifugal purification. The encapsulation efficiency of methotrexate was $21.7 \%$. To endow the MTX-PEI NPs with targetability, the particles were further coated with a layer of HA via electrostatic force, which enables MTX-PEI NPs to recognize the activated macrophages through the overexpressed CD44 receptor on cell membrane. MTX-PEI NPs@HA were obtained by using the method mentioned above. Then, after lyophilization, 
the nanoparticles were weighed and the drug loading of MTX was calculated to be $37.4 \%$. Next, transmission electron microscopy (TEM) was performed to observe the morphological characteristics of different nanoparticles. Compared with MTX-PEI NPs, MTX-PEI@HA NPs owned different morphological characteristics as observed in TEM images (Figure 2b). The result also showed that MTX-PEI@HA NPs were spherical. It should be noted that the core of MTX/PEI@HA NPs formed by electrostatic interaction was relatively loose and the shape was irregular when compared with MTX-PEI@HA (Figure 2a,b). The particle sizes of MTX-PEI and MTX-PEI@HA were $160 \pm 9 \mathrm{~nm}$ and $216 \pm 7 \mathrm{~nm}$, respectively. The increase of particle size indicated the successful coating of HA. The NPs were dispersed in pure water, and then Zeta potential was measured. Results showed that the HA coating reversed the zeta potential of MTX-PEI particles from positive $(19.4 \pm 1.2 \mathrm{mv})$ to negative $(-15.8 \pm 1.5 \mathrm{mv})$ (Figure 2c,d).

For biological applications, the nano-system should be stable enough under physiological conditions for in vivo delivery. Because drug release behavior reflects the stability of preparation, we study the release kinetics of the MTX. MTX/PEI@HA and MTX-PEI@HA NPs were immersed in $10 \mathrm{mM}$ PBS (pH 7.2) at $37^{\circ} \mathrm{C}$ to determine released MTX as a function of time by the HPLC method (Figure 2e). MTX/PEI@HA NPs showed a biphasic release pattern of MTX with an initial burst, followed by a sustained release for $48 \mathrm{~h}$. Up to $50 \%$ of the MTX in MTX/PEI@HA NPs released in $0.5 \mathrm{~h}$. In contrast, MTX-PEI@HA NPs showed a sustained release in microscale $(2.1 \%)$ in $48 \mathrm{~h}$. The results demonstrated the amide bond between MTX and PEI was stable. Because of this, the preparation (MTX-PEI@HA) may avoid drug leakage before reaching the target tissue. Therefore, MTX-PEI@HA NPs were chosen as a final preparation used in further experiments.

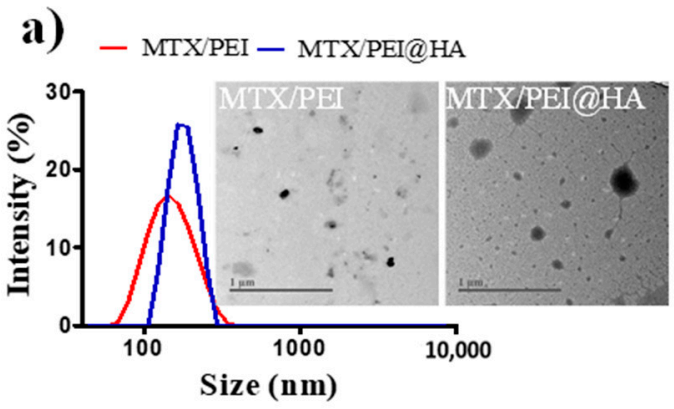

c)

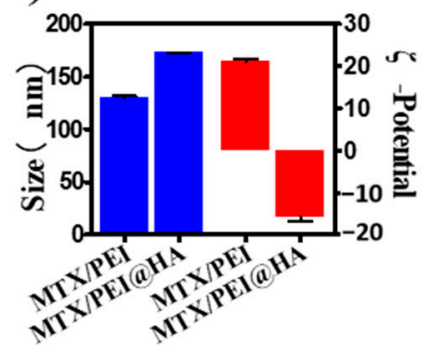

d)
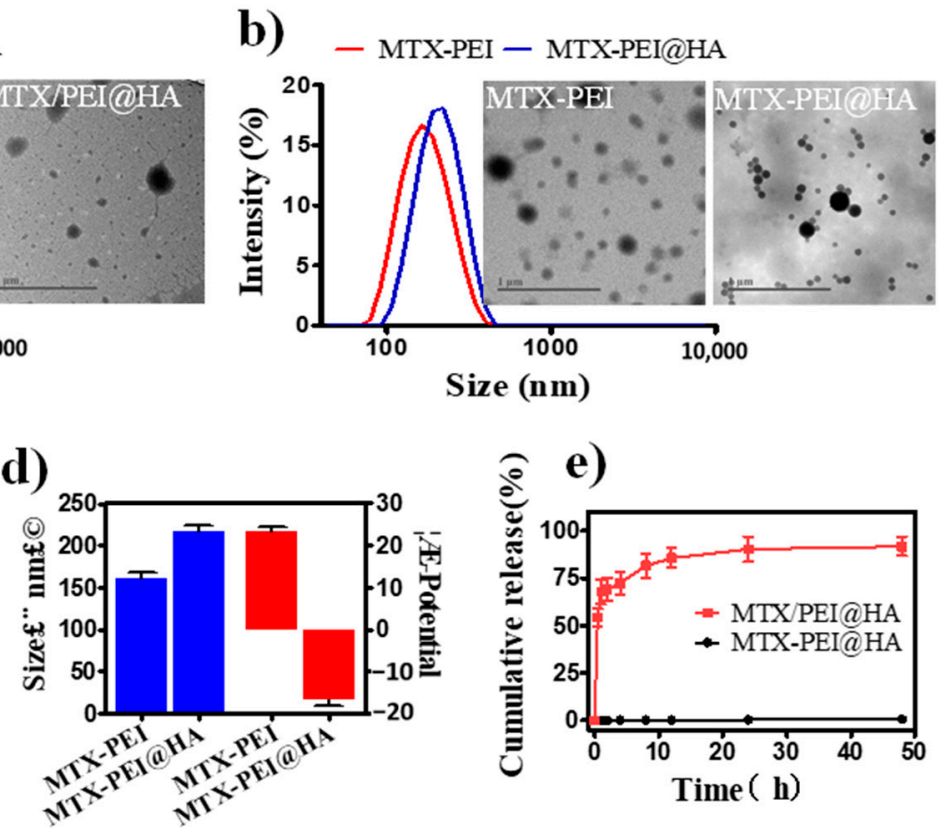

Figure 2. Physicochemical characteristics of MTX NPs. Physicochemical characterization of MTX/PEI NPs (a) and MTX-PEI NPs (b) with or without HA coating by using transmission electron microscopy and DLS. Scale bar $=1 \mu \mathrm{m}$. (c,d) Zeta potential and size analysis of MTX/PEI, MTX/PEI@HA, MTX-PEI and MTX-PEI@HA NPs in ultrapure water. (e) In vitro release kinetics of MTX from MTX/PEI@HA NPs and MTX-PEI@HA NPs. All data represent means \pm S.D. of three measurements.

\subsection{In Vitro Cellular Uptake and Anti-Inflammatory Activity of the MTX-PEI@HA NPs}

After systematic characterizations, we next studied the intracellular performances of the MTX-PEI@HA NPs. The cellular uptake was assessed by using the activated macrophages because of their crucial role in the RA progression and thus are the main target in therapy. First, we used LPS to activate macrophages and increase CD44 expression on the cell membrane. RT-PCR was conducted to observe the establishment of an activated macrophage. The activated 
macrophage markers (iNOs, TNF- $\alpha$, IL-1 $\beta$, IL-6) were significantly increased (Figure S1, from supplementary materials) and these results confirmed the successful induction of activated macrophage. RAW264.7 macrophages cells were treated with 5-FAM labeled MTX-PEI@HA NPs (green fluorescence). In these experiments, macrophages were activated with LPS to induce the upregulation of the CD44 receptor. [40,41] Fluorescence images showed that little MTX-PEI@HA NPs was internalized into the RAW 264.7 (LPS-) at $37^{\circ} \mathrm{C}$. However, much stronger fluorescence signals were detected in RAW264.7 cells (LPS+) after $4 \mathrm{~h}$ incubation with the NPs (Figure 3a). Interestingly, weak fluorescent signals were observed in the cells pretreated with the HA to block the CD44 receptor mediating endocytosis. Analysis using flow cytometer confirmed that the ratio of MTX-PEI@HA NPs delivered into RAW264.7 cells (LPS+) to RAW 264.7 (LPS-) is 2.2 (Figure 3b,c). The results might demonstrate that the NPs can selectively target activated macrophages via the CD44 receptor-mediated endocytosis pathway.

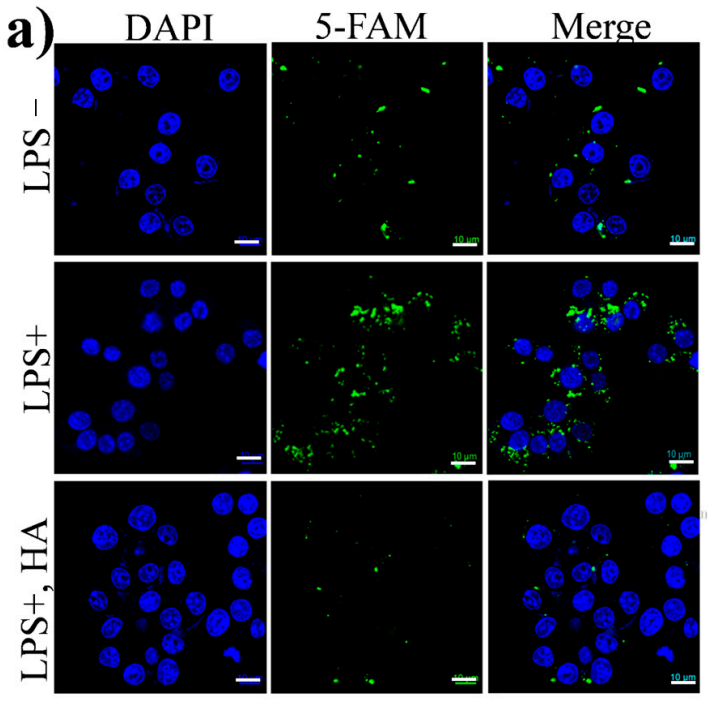

b)

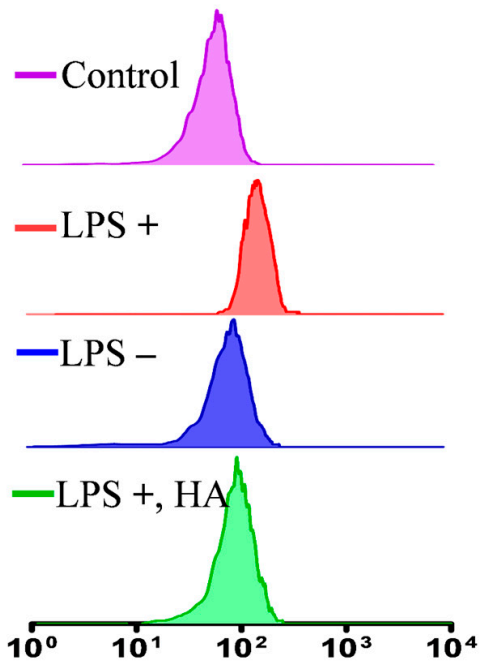

c)
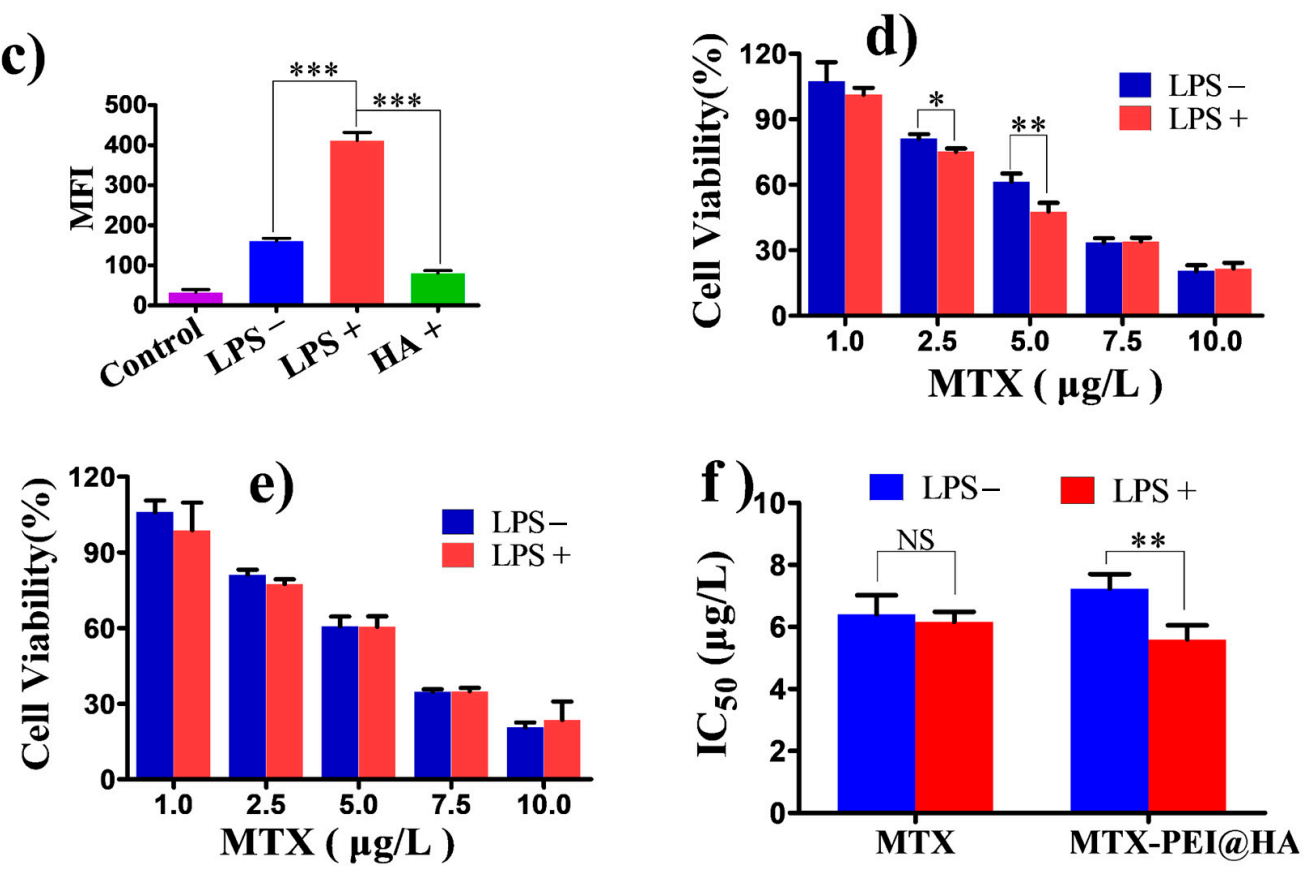

Figure 3. In vitro cellular uptake of MTX-PEI@HA NPs in murine macrophage RAW 264.7 cells. (a) Confocal laser scanning microscope images of RAW 264.7 cells treated with 5-carboxyfluorescein (5-FAM)-labeled MTX-PEI@HA NPs. Scale bar = $10 \mu \mathrm{m}$. (b) Flow cytometric graphs of fluorescent intensity of 5-FAM in macrophages that treated as listed. (c) Quantitation of mean fluorescence intensity (MFI) from (b). (d,e) Viability of RAW264.7 cells (before and after activation by LPS) after incubation with MTX-PEI@HA NPs for 72 h. (f) IC50 values calculated from (d,e). ${ }^{*} p<0.05,{ }^{* *} p<0.01,{ }^{* * *} p<0.001$. 
We then studied the in vitro anti-inflammatory activity of MTX-PEI@HA NPs via using MTT assay. Normal macrophages and the activated macrophages were incubated with MTX-PEI@HA NPs for 72 h. After treatment, both normal macrophages and the activated macrophages displayed a concentration dependent cytotoxicity (Figure $3 \mathrm{~d}$ ). Interestingly, we found notably lower cell viability of the activated macrophages at the MTX concentration of 2.5 and $7.5 \mu \mathrm{g} / \mathrm{L}$ compared with normal macrophages. However, cell viability was no different at various concentrations in the control group (treated with free MTX) (Figure 3e). By comparing IC50 (50\% inhibiting concentration) values, MTXPEI@HA NPs was much more toxic to activated macrophages when compared with normal macrophages. The results verified that the activated macrophages can selectively uptake MTX-PEI@HA NPs via CD44 receptors.

\subsection{Therapeutic Effect of MTX-PEI@HA NPS on Rheumatoid Arthritis (RA)}

Finally, we investigated the therapeutic efficacy of MTX-PEI NPs following the treatment scheme outline (Figure $4 \mathrm{a}$ ). The CIA mice model was established via subcutaneous injection of collagen. MTX-PEI@HA NPs was administered to CIA mice via intravenous injection. The other groups treated with PBS, free MTX, and MTX-PEI as controls via intravenous injection. The extent of paw swelling was used as a direct indicator of RA. Thus, paw swelling was observed overtime as an index of arthritis. To evaluate the efficacy, photographs of hind paws were taken before and after the treatments. As shown in Figure $4 b$, there was only slight swelling or erythema confined to the peripheral joints in the group treated with MTX-PEI@HA NPs, whereas the untreated PBS control group showed severe swelling of entire paw. Compared with the PBS group, MTX and MTX-PEI groups showed therapeutic effect but lower efficacy than MTX-PEI@HA group. To quantify this, we measured the thickness of hind paw to further evaluate swelling degree during the treatment. As shown in Figure 4c, the mean thickness of hind paws continued to decrease in MTX-PEI@HA group and indicated more pronounced decline trend than other groups after the first injection. Figure $4 \mathrm{~d}$ shows the mean hind paw thickness in different groups two days after the last injection and the value of MTX-PEI@HA group was significantly lower than that of other groups, indicating a better outcome of CIA mice treated with MTX-PEI@HA NPs. The clinical score results in each group were consistent with the results above (Figure 4e,f). The efficacy was concluded to be MTX-PEI@HA NPs > MTX-PEI NPs > free MTX > PBS.

The therapeutic efficacy was further evaluated by examination of H\&E-stained histological slides of ankle joints. Ankle joint sections from MTX-PEI@HA NPs-treated mice showed normal cartilage surfaces with a clear interface, while examination of H\&E-stained histological slides of ankle joints revealed extensive pannus formation and severe bone destruction in PBS group, which translated in the highest histological synovitis score (HSS > 8.0). Although the mice treated with free MTX showed less extensive cartilage damage, inflammatory cell infiltration and pannus formation were still obvious. Mice injected with the MTX-PEI@HA NPs group exhibited the lowest HSS values $(<5.0)$ among the treatment groups and revealed minimal pathological features, including synovial hyperplasia, pannus formation, cartilage destruction, and bone erosion (Figure $4 \mathrm{~g}$, $\mathrm{h}$ ).

We further measured the levels of pro-inflammatory cytokines in joints as another index to assess the therapeutic efficacy via tissues Western blotting. For the PBS-treated mice, the cytokines including TNF- $\alpha$ and IL-6 remained at high levels (Figure $4 \mathrm{i}, \mathrm{j}$ ), while MTX-PEI@HA NPs could reduce the cytokines almost to a normal level, demonstrating their good anti-inflammation activity. The cytokine levels also significantly decreased after MTX-PEI NPs and MTX treatment, while the efficacy was much lower. All the results mentioned above demonstrated that MTX-PEI@HA NPs had advantage over other formulations and might indicate the superiority for HA-coated MTX-PEI NPs. 
a)

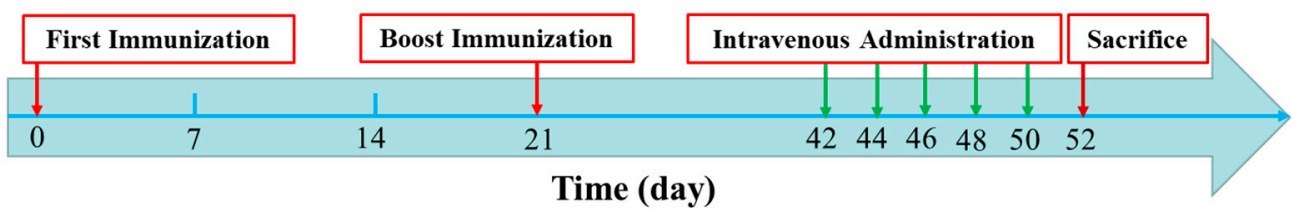

b)

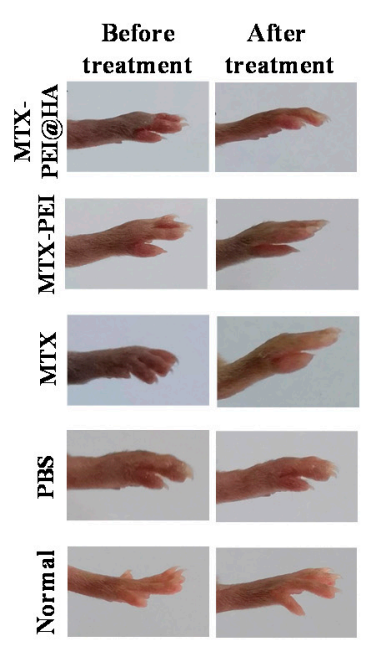

c)

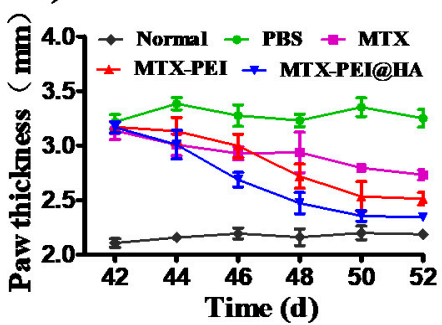

e)

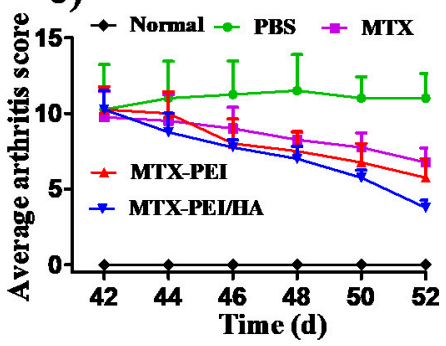

d)
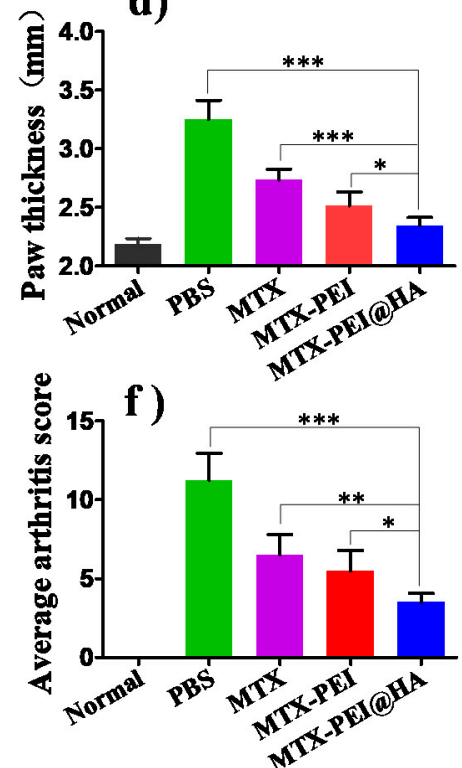
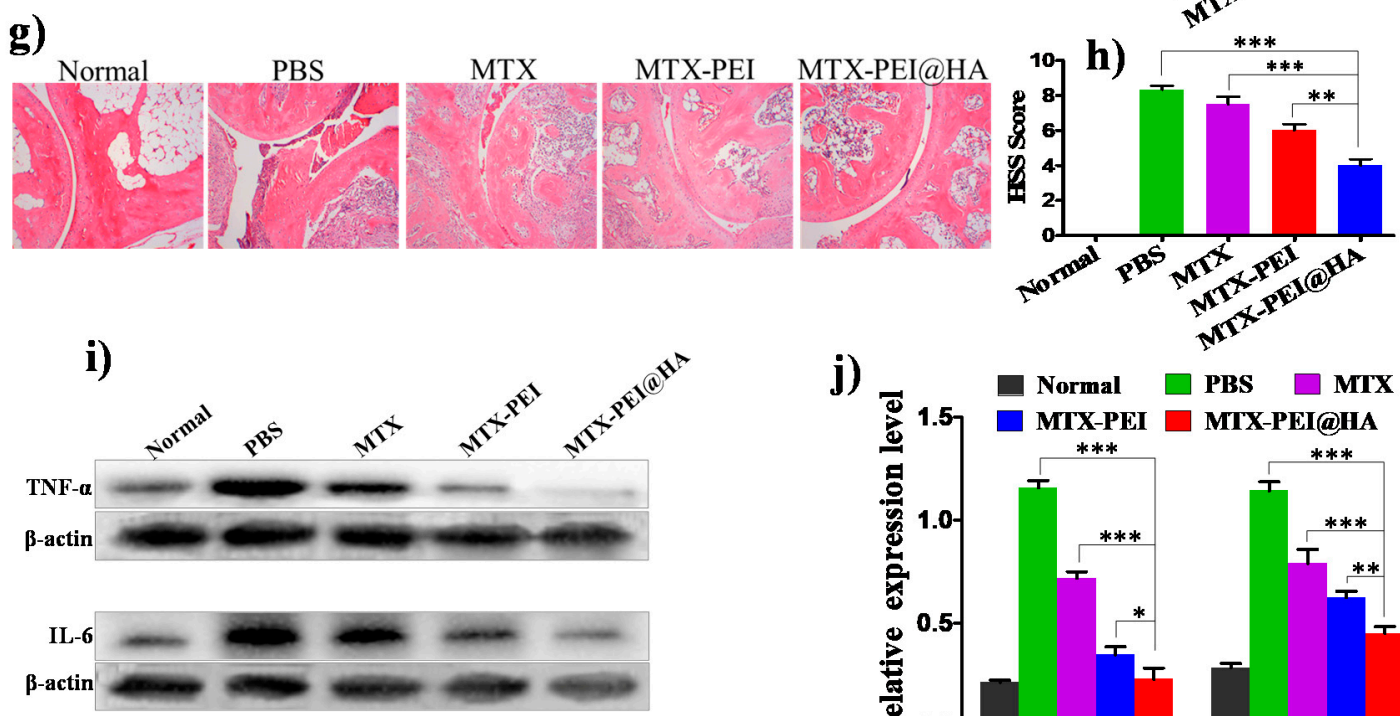

j)

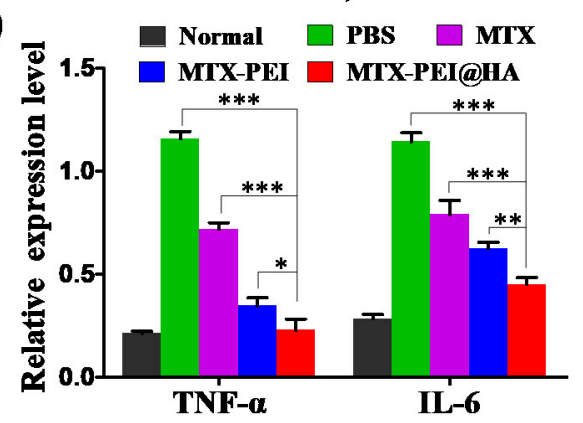

Figure 4. Therapeutic efficacy of MTX-PEI@HA NPs in collagen-induced arthritis (CIA) mice. (a) The overall experimental timeline for in vivo experiment. (b) Photographs of DBA/1 mice paws treated with different formulations. (c) The severity of arthritis assessed by measuring hind paw thickness over time (d) The hind paw thickness measured 2 days after the last injection. (e) Mice were scored according to the disease progression. (f) The clinical arthritis score evaluated 2 days after the last injection. (g) Histological analysis with hematoxylin-eosin (H\&E) of joint tissues extracted from mice of different treatment groups. (h) Histological synovitis score (HSS) of joint tissues extracted from different treatment groups. (i) The inflammatory cytokine (IL-6, TNF- $\alpha$ ) levels in joints of the mice detected by Western blot after different treatment. ( $\mathbf{j}$ ) Semi-quantitative image analysis of the bands from (i). ${ }^{*} p<0.05,{ }^{* *} p<0.01,{ }^{* * *} p<0.001$.

\subsection{Systemic Toxicity of MTX-PEI@HA NPs}

Prolonged high-dose MTX usually lead to serious systemic toxicity. In order to reduce the side effects, a low dosage of MTX is usually adminstered via intramuscular injection, subcutaneous injection, or oral in treatment of rheumatoid arthritis. Considering that the 
advantages of MTX-based nanoplatform in reducing side effects have been reported, we adminstered a relatively high dose of MTX $(5 \mathrm{mg} / \mathrm{kg})$ via intravenous injection according to the previous report [29]. For safety concerns, we further examined if the treatment by MTX-PEI@HA NPs cause the relevant pathological damage in major organs. We performed histopathological analysis of organs including the liver, spleen and kidneys extracted from DBA/1 mice. Histological slides of organs were prepared, stained with H\&E, and imaged to further evaluate the potential systemic side-effects of free MTX, MTX-PEI NPs and MTX-PEI@HA NPs. No necrotic tissue was found in the liver and spleen of each group. Moreover, the structure of glomeruli was normal, and no necrotic cells were found in the renal tissue of each group. The results indicated no obvious systemic toxicity of MTX-PEI@HA NPs (Figure 5a).

a)
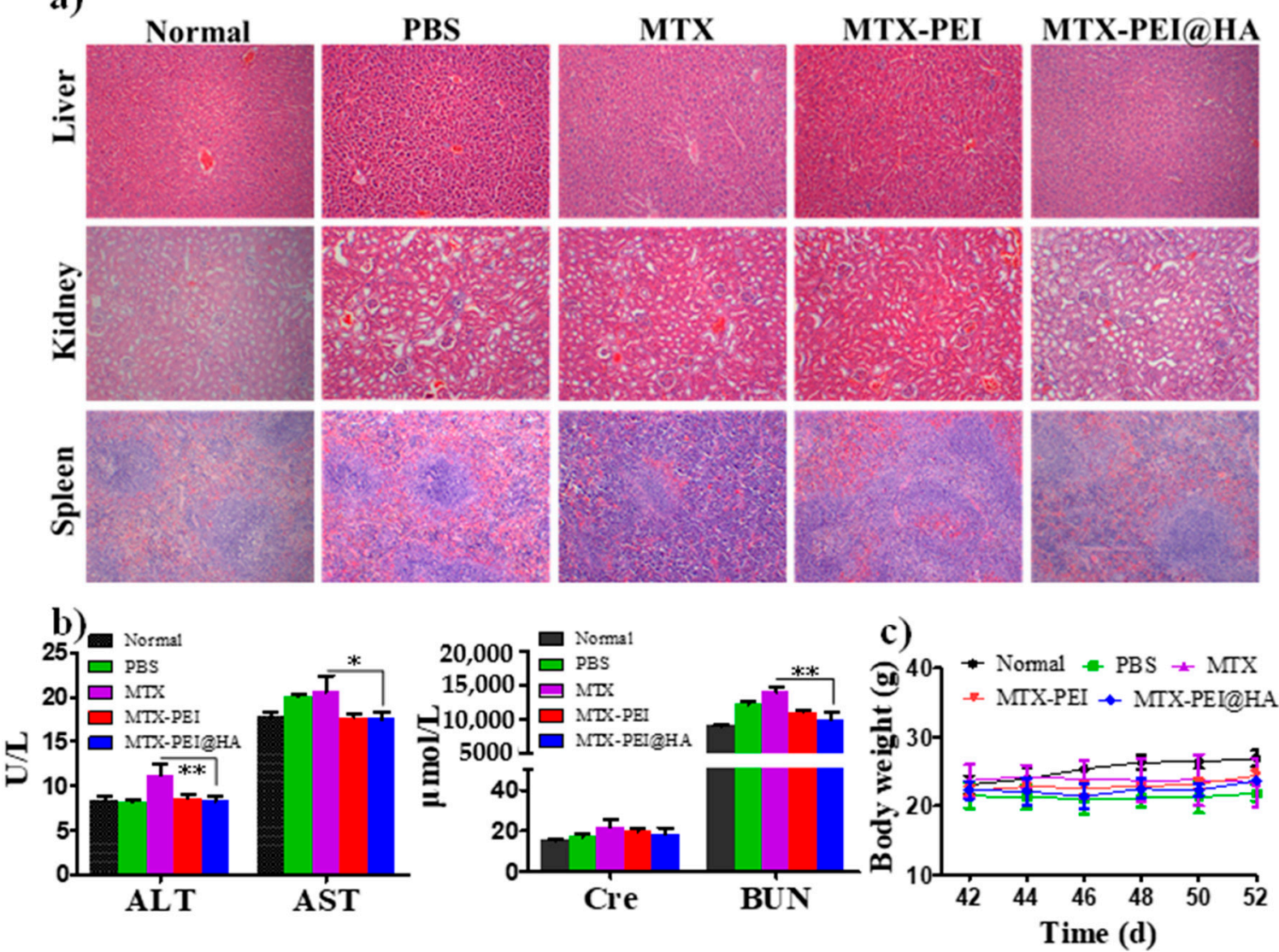

Figure 5. Systemic toxicity assessment of MTX-PEI@HA NPs. (a) H\&E-stained images of liver, kidney and spleen. (b) Evaluation of the hepatotoxicity (according to the serum levels of alanine aminotransferase (ALT), aspartate aminotransferase (AST)) and nephrotoxicity (according to the serum levels of BUN and Cre) after different treatments. ${ }^{*} p<0.05,{ }^{* *} p<0.01$. (c) Body weight fluctuation of mice with different treatments during 10 days.

Serum samples were also collected two days after the last injection to evaluate the toxicity of MTX-PEI@HA NPs. Hepatotoxicity was determined by measuring the aspartate transaminase (AST) and alanine aminotransferase (ALT) in serum samples. Nephrotoxicity was evaluated by measuring the serum blood urea nitrogen (BUN) and creatinine (Cre). All four blood biochemical indexes were negligibly changed after MTX-PEI@HANPs treatment compared to normal mice (Figure 5b). These results further validated that MTX-PEI@HA NPs did not cause obvious systemic toxicity. For MTX-treated group, by contrast, AST, AST, and BUN levels increased obviously, which might indicate liver and renal injury after long-term MTX administration. Hemolysis test was performed on mouse red blood cells. As displayed in Figure S2 from supplementary materials, the i.v. injection of MTX-PEI@HA 
NPs at the highest dosage $(100 \mu \mathrm{g} / \mathrm{mL})$ did not cause obvious hemolysis of the red blood cells. Furthermore, we measured body weight of the mice in each group over the whole treatment process to assess systemic toxicity of each formulation. The results indicated that MTX-PEI@HA NPs did not cause significant weight change. In summary, MTX-PEI@HA NPs seem to be a better choice owing to their higher bio-safety and better outcomes.

\section{Conclusions}

In this study, we reported the application of PEI as a nanocarrier in MTX delivery for targeted RA therapy and tried to construct a nanoplatform via electrostatic force between PEI and MTX. While electrostatic interaction was straightforward and simple, we found that it was incompetent for in vivo application due to premature drug release. Therefore, we synthesized MTX-PEI NPs in water phase via chemical bonding and then coated with HA. The results of in vitro experiments indicated that MTX-PEI@HA NPs were selectively internalized by activated macrophages and possessed target cytotoxicity ability. The active target ability depended on hyaluronic acid receptor (CD44)-mediated endocytosis. MTXPEI@HA NPs also showed enhanced anti-rheumatoid arthritis effects and biosafety in in vivo studies as compared to free MTX, which might benefit from target delivery and slow release of MTX in vivo. This work provides a PEI-based nanoplatform to deliver MTX for target RA treatment, and call attention to biological use of nanocomposites derived from electrostatic interaction between small molecule drug and cationic polymers, which may promote the practical applications of cationic materials in drug delivery.

Supplementary Materials: The following are available online at https: / www.mdpi.com/2073-435 2/11/4/321/s1, Figure S1: RT-PCR test to verify the establishment of activated macrophages, Figure S2: Hemolysis of MTX-PEI@HA NPs at various concentrations on mouse red blood cells.

Author Contributions: Conceptualization, W.Z., J.D. and S.Z.; validation, W.Z., J.D. and S.Z.; investigation, S.Z., P.L.; resources, W.Z. and J.D.; data curation, S.Z. and P.L.; writing—original draft preparation, S.Z. and P.L.; writing-review and editing, W.Z., J.D. and P.L.; supervision, W.Z., and J.D.; funding acquisition, W.Z., and J.D. All authors have read and agreed to the published version of the manuscript.

Funding: This research was funded by Innovation-Driven Project of Central South University (No. 20170030010004), National Natural Science Foundation of China (No. 21804144, 81573374), Hunan Engineering Research Center for Optimization of Drug Formulation and Early Clinical Evaluation (No. 2015TP2005), Science and Technology Projects of Jiangxi Provincial Department of Education (GJJ180849), and APC was funded by Science and Technology Projects of Jiangxi Provincial Department of Education (GJJ180849).

Institutional Review Board Statement: The study was conducted according to the guidelines of the Declaration of Helsinki and approved by "Ethics Committee of Laboratory Animal Welfare of Central South University" (protocol code No. 2019-0004/20.03.2019).

Informed Consent Statement: Not applicable.

Data Availability Statement: Not applicable.

Conflicts of Interest: The authors declare no conflict of interest.

\section{References}

1. Smolen, J.S.; Aletaha, D.; Barton, A.; Burmester, G.R.; Emery, P.; Firestein, G.S.; Kavanaugh, A.; McInnes, I.B.; Solomon, D.H.; Strand, V.; et al. Rheumatoid arthritis. Nat. Rev. Dis. Primers 2018, 4, 18001. [CrossRef] [PubMed]

2. Firestein, G.S.; McInnes, I.B. Immunopathogenesis of Rheumatoid Arthritis. Immunity 2017, 46, 183-196. [CrossRef]

3. Malmstrom, V.; Catrina, A.I.; Klareskog, L. The immunopathogenesis of seropositive rheumatoid arthritis: From triggering to targeting. Nat. Rev. Immunol. 2017, 17, 60-75. [CrossRef]

4. Guo, Q.; Wang, Y.; Xu, D.; Nossent, J.; Pavlos, N.J.; Xu, J. Rheumatoid arthritis: Pathological mechanisms and modern pharmacologic therapies. Bone Res. 2018, 6, 15. [CrossRef]

5. Burmester, G.R.; Pope, J.E. Novel treatment strategies in rheumatoid arthritis. Lancet 2017, 389, 2338-2348. [CrossRef]

6. Siouti, E.; Andreakos, E. The many facets of macrophages in rheumatoid arthritis. Biochem. Pharmacol. 2019, 165, 152-169. [CrossRef] [PubMed] 
7. Liu, W.; Zhang, Y.; Zhu, W.; Ma, C.; Ruan, J.; Long, H.W.Y. Sinomenine Inhibits the Progression of Rheumatoid Arthritis by Regulating the Secretion of Inflammatory Cytokines and Monocyte/Macrophage Subsets. Front. Immunol. 2018, 9, 2228. [CrossRef]

8. $\quad$ Ledingham, J.; Gullick, N.; Irving, K.; Gorodkin, R.; Aris, M.; Burke, J.; Gordon, P.; Christidis, D.; Galloway, S.; Hayes, E.; et al. BSR and BHPR guideline for the prescription and monitoring of non-biologic disease-modifying anti-rheumatic drugs. Rheumatology 2017, 56, 865-868. [CrossRef]

9. Song, G.G.; Bae, S.C.; Lee, Y.H. Association of the MTHFR C677T and A1298C polymorphisms with methotrexate toxicity in rheumatoid arthritis: A meta-analysis. Clin. Rheumatol. 2014, 33, 1715-1724. [CrossRef]

10. Qiu, Q.; Huang, J.; Shu, X.; Fan, H.; Zhou, Y.; Xiao, C. Polymorphisms and Pharmacogenomics for the Clinical Efficacy of Methotrexate in Patients with Rheumatoid Arthritis: A Systematic Review and Meta-analysis. Sci. Rep. 2017, 7, 44015. [CrossRef]

11. Lee, Y.H.; Bae, S.C.; Song, G.G. Association of the ABCB1 C3435T polymorphism with responsiveness to and toxicity of DMARDs in rheumatoid arthritis: A meta-analysis. Z Rheumatol. 2016, 75, 707-715. [CrossRef]

12. Van der Heijde, D.; Breedveld, F.C.; Kavanaugh, A.; Keystone, E.C.; Landewe, R.; Patra, K.; Pangan, A.L. Disease activity, physical function, and radiographic progression after longterm therapy with adalimumab plus methotrexate: 5-year results of PREMIER. J. Rheumatol. 2010, 37, 2237-2246. [CrossRef]

13. Wluka, A.; Buchbinder, R.; Mylvaganam, A.; Hall, S.; Harkness, A.; Lewis, D.; Littlejohn, G.O.; Miller, M.H. Ryan, P.F.J. Long-term methotrexate use in rheumatoid arthritis: 12 years followup of 460 patients treated in community practice. J. Rheumatol. 2000, 27, 1864-1871.

14. Van der Heijden, J.W.; Dijkmans, B.A.C.; Scheper, R.J.; Jansen, G. Drug Insight: Resistance to methotrexate and other diseasemodifying antirheumatic drugs-from bench to bedside. Nat. Clin. Pract. Rheumatol. 2007, 3, 26-34. [CrossRef]

15. Abolmaali, S.S.; Tamaddon, A.M.; Dinarvand, R. A review of therapeutic challenges and achievements of methotrexate delivery systems for treatment of cancer and rheumatoid arthritis. Cancer Chemother. Pharmacol. 2013, 71, 1115-1130. [CrossRef]

16. Guo, L.N.; Chen, Y.; Wang, T.; Yuan, Y.; Yang, Y.H.; Luo, X.L.; Hu, S.; Ding, J.S.; Zhou, W.H. Rational design of metal-organic frameworks to deliver methotrexate for targeted rheumatoid arthritis therapy. J. Control Release 2021, 330, 119-131. [CrossRef] [PubMed]

17. Ramos, A.P.; Cruz, M.A.E.; Tovani, C.B.; Ciancaglini, P. Biomedical applications of nanotechnology. Biophys. Rev. 2017, 9, 79-89. [CrossRef] [PubMed]

18. Xiao, S.; Tang, Y.; Lv, Z.; Lin, Y.; Chen, L. Nanomedicine-advantages for their use in rheumatoid arthritis theranostics. J. Control Release 2019, 316, 302-316. [CrossRef]

19. Prasad, L.K.; O'Mary, H.; Cui, Z. Nanomedicine delivers promising treatments for rheumatoid arthritis. Nanomedicine 2015, 10, 2063-2074. [CrossRef] [PubMed]

20. Rahman, M.; Sharma, G.; Thakur, K.; Anwar, F.; Katare, O.P.; Goni, V.G.; Kumar, V.; Zamzami, M.A.; Akhter, S. Emerging Advances in Nanomedicine as a Nanoscale Pharmacotherapy in Rheumatoid Arthritis: State of the Art. Curr. Top. Med. Chem. 2017, 17, 162-173. [CrossRef]

21. Appel, H.; Loddenkemper, C.; Miossec, P. Rheumatoid arthritis and ankylosing spondylitis-pathology of acute inflammation. Clin. Exp. Rheumatol. 2009, 27, S15-S19.

22. Oore-ofe, O.; Soma, P.; Buys, A.V.; Debusho, L.K.; Pretorius, E. Characterizing pathology in erythrocytes using morphological and biophysical membrane properties: Relation to impaired hemorheology and cardiovascular function in rheumatoid arthritis. Biochim. Biophys. Acta Biomembr. 2017, 1859, 2381-2391. [CrossRef]

23. Oliveira, I.M.; Goncalves, C.; Reis, R.L.; Oliveira, J.M. Engineering nanoparticles for targeting rheumatoid arthritis: Past, present, and future trends. Nano Res. 2018, 11, 4489-4506. [CrossRef]

24. Jahangirian, H.; Lemraski, E.G.; Webster, T.J.; Rafiee-Moghaddam, R.; Abdollahi, Y. A review of drug delivery systems based on nanotechnology and green chemistry: Green nanomedicine. Int. J. Nanomed. 2017, 12, 2957-2977. [CrossRef] [PubMed]

25. Fan, W.; Yung, B.; Huang, P. Chen, X. Nanotechnology for Multimodal Synergistic Cancer Therapy. Chem. Rev. 2017, 117, 13566-13638. [CrossRef]

26. Alivisatos, A.P. Less is more in medicine-Sophisticated forms of nanotechnology will find some of their first real-world applications in biomedical research, disease diagnosis and, possibly, therapy. Sci. Am. 2001, 285, 66-73. [CrossRef]

27. Choi, K.Y.; Saravanakumar, G.; Park, J.H.; Park, K. Hyaluronic acid-based nanocarriers for intracellular targeting: Interfacial interactions with proteins in cancer. Colloids Surf. B Biointerfaces 2012, 99, 82-94. [CrossRef]

28. Cadete, A.; Alonso, M.J. Targeting cancer with hyaluronic acid-based nanocarriers: Recent advances and translational perspectives. Nanomedicine 2016, 11, 2341-2357. [CrossRef]

29. Alam, M.M.; Han, H.S.; Sung, S.; Kang, J.H.; Sa, K.H.; Al Faruque, H.; Hong, J.; Nam, E.J.; Kim, I.S.; Park, J.H.; et al. Endogenous inspired biomineral-installed hyaluronan nanoparticles as $\mathrm{pH}$-responsive carrier of methotrexate for rheumatoid arthritis. $J$. Control Release 2017, 252, 62-72. [CrossRef] [PubMed]

30. Gouveia, V.M.; Lopes-de-Araujo, J.; Lima, S.A.C.; Nunes, C.; Reis, S. Hyaluronic acid-conjugated pH-sensitive liposomes for targeted delivery of prednisolone on rheumatoid arthritis therapy. Nanomedicine 2018, 13, 1037-1049. [CrossRef] [PubMed]

31. Zhou, M.L.; Hou, J.R.; Zhong, Z.R.; Hao, N.; Lin, Y. Li, C.H. Targeted delivery of hyaluronic acid-coated solid lipid nanoparticles for rheumatoid arthritis therapy. Drug Deliv. 2018, 25, 716-722. [CrossRef] [PubMed] 
32. Lee, J.; Luria, A.; Rhodes, C.; Raghu, H.; Lingampalli, N.; Sharpe, O.; Rada, B.; Sohn, D.H.; Robinson, W.H.; Sokolove, J. Nicotine drives neutrophil extracellular traps formation and accelerates collagen-induced arthritis. Rheumatology 2017, 56, 644-653. [CrossRef] [PubMed]

33. Liu, H.; Ding, J.; Wang, J.; Wang, Y.; Yang, M.; Zhang, Y.; Chang, F.; Chen, X. Remission of Collagen-Induced Arthritis through Combination Therapy of Microfracture and Transplantation of Thermogel-Encapsulated Bone Marrow Mesenchymal Stem Cells. PLoS ONE 2015, 10, e0120596. [CrossRef]

34. Liu, H.; Ding, J.X.; Wang, C.Y.; Wang, J.C.; Wang, Y.N.; Yang, M.D.; Jia, Y.L.; Zhang, Y.B.; Chang, F.; Li, R.; et al. Intra-Articular Transplantation of Allogeneic BMMSCs Rehabilitates Cartilage Injury of Antigen-Induced Arthritis. Tissue Eng. Part A 2015, 21, 2733-2743. [CrossRef] [PubMed]

35. Haleagrahara, N.; Miranda-Hernandez, S.; Alim, M.A.; Hayes, L.; Bird, G.; Ketheesan, N. Therapeutic effect of quercetin in collagen-induced arthritis. Biomed. Pharmacother. 2017, 90, 38-46. [CrossRef] [PubMed]

36. Zhang, S.; Zhao, B.; Jiang, H.; Wang, B.; Ma, B. Cationic lipids and polymers mediated vectors for delivery of siRNA. J. Control Release 2007, 123, 1-10. [CrossRef]

37. Xia, T.; Kovochich, M.; Liong, M.; Meng, H.; Kabehie, S.; George, S.; Zink, J.I.; Nel, A.E. Polyethyleneimine coating enhances the cellular uptake of mesoporous silica nanoparticles and allows safe delivery of siRNA and DNA constructs. ACS Nano 2009, 3, 3273-3286. [CrossRef]

38. Lim, W.K.; Rosgen, J.; Englander, S.W. Urea, but not guanidinium, destabilizes proteins by forming hydrogen bonds to the peptide group. Proc. Natl. Acad. Sci. USA 2009, 106, 2595-2600. [CrossRef]

39. Higuchi, S.; Satoh, M. Effects of $\mathrm{NaCl}, \mathrm{NaOH}$, and $\mathrm{HCl}$ concentration on the cloud point of poly (vinyl methyl ether) in water-electrostatic interactions are inevitably involved in the hydrophobic interaction. Colloid Polym. Sci. 2017, 295, 1511-1520. [CrossRef]

40. Thanh-Huyen, T.; Rastogi, R.; Shelke, J.; Amiji, M.M. Modulation of Macrophage Functional Polarity towards Anti-Inflammatory Phenotype with Plasmid DNA Delivery in CD44 Targeting Hyaluronic Acid Nanoparticles. Sci. Rep. UK 2015, 5, 16632.

41. Farajzadeh, R.; Zarghami, N.; Serati-Nouri, H.; Momeni-Javid, Z.; Farajzadeh, T.; Jalilzadeh-Tabrizi, S.; Sadeghi-Soureh, S.; Naseri, N.; Pilehvar-Soltanahmadi, Y. Macrophage repolarization using CD44-targeting hyaluronic acid-polylactide nanoparticles containing curcumin. Artif. Cells Nanomed. Biotechnol. 2018, 46, 2013-2021. [CrossRef] [PubMed] 